\title{
Cytocompatibility of Direct Laser Interference-patterned Titanium Surfaces for Implants
}

\author{
PHILIP HARTJEN $^{1 *}$, OLA NADA ${ }^{1 *}$, THIAGO GUNDELWEIN SILVA ${ }^{1}$, CLARISSA PRECHT $^{1}$, \\ ANDERS HENNINGSEN ${ }^{1}$, MARZELLUS GROßE HOLTHAUS ${ }^{2}$, NIKOLAI GULOW ${ }^{2}$, \\ REINHARD E. FRIEDRICH ${ }^{1}$, HENNING HANKEN ${ }^{1}$, MAX HEILAND ${ }^{3}$, \\ CHRISTOPH ZWAHR ${ }^{4,5}$, RALF SMEETS ${ }^{1}$ and OLE JUNG ${ }^{1}$ \\ ${ }^{1}$ Department of Oral and Maxillofacial Surgery, \\ University Medical Center Hamburg-Eppendorf, Hamburg, Germany; \\ ${ }^{2}$ BEGO Implant Systems GmbH \& Co. KG, Bremen, Germany; \\ ${ }^{3}$ Department of Oral and Maxillofacial Surgery, Charité University Hospital, Berlin, Germany; \\ ${ }^{4}$ Institute of Manufacturing Technology, TU Dresden, Dresden, Germany; \\ ${ }^{5}$ Fraunhofer Institute for Material and Beam Technology, Dresden, Germany
}

\begin{abstract}
In an effort to generate titanium surfaces for implants with improved osseointegration, we used direct laser interference patterning (DLIP) to modify the surface of pure titanium grade 4 of four different structures. We assessed in vitro cytoxicity and cell attachment, as well as the viability and proliferation of cells cultured directly on the surfaces. Attachment of the cells to the modified surfaces was comparably good compared to that of cells on gritblasted and acid-etched reference titanium surfaces. In concordance with this, viability and proliferation of the cells directly cultured on the specimens were similar on all the titanium surfaces, regardless of the laser modification, indicating good cytocompatibility.
\end{abstract}

Improving the osseointegration of implants is a key issue in dental implantation and surface modification is a major strategy for enhancing the attachment, proliferation and differentiation of cells in contact with such implants.

For titanium implants, various methods are used to modify the surface roughness, including sandblasting, acid-etching, anodization, calcium-phosphate crystal deposition and chemical modification (1).

This article is freely accessible online.

*These Authors contributed equally to this study.

Correspondence to: Philip Hartjen, Department of Oral and Maxillofacial Surgery, University Medical Center Hamburg-Eppendorf, Martinistrasse 52, 20246 Hamburg. E-mail: p.hartjen@uke.de

Key Words: Direct laser interference, titanium implants, cytocompatibility.
A recently developed technique for surface modification is direct laser interference patterning (DLIP) $(2,3)$. By overlapping two or more laser beams on a sample surface, periodic laser intensity distributions are obtained and used for laser ablation. DLIP is a very cost effective process for treating surfaces because it is possible to structure metals at high speeds of up to $0.39 \mathrm{~m}^{2} / \mathrm{min}$ (4). The structure periodicity can be controlled at the micrometer to submicrometer range and the surface roughness at the micrometer to nanometer level. Moreover, some chemical features can be modified, for example, the material's wetting properties (5).

In the present study, we modified the surface of titanium of four different structures and assessed in vitro cytoxicity and cell attachment, as well as the viability and proliferation of cells cultured directly on the surfaces.

\section{Materials and Methods}

Titanium specimens and reference materials. Line-like structures with spatial periods (p) of 3, 5, 10 and $20 \mu \mathrm{m}$ were produced on pure titanium (grade IV) samples (Figure 1). All specimens were cylindrical with a diameter of $10 \mathrm{~mm}$ and thickness of $1.5 \mathrm{~mm}$. Before and after laser treatment they were cleaned in pure ethanol $\left(\mathrm{C}_{2} \mathrm{H}_{5} \mathrm{OH}\right)$ using ultrasonic cleaning for $5 \mathrm{~min}$ each. As a reference surface, standard grit-blasted and etched samples (TiPure Plus; Bego Implant Systems, Bremen, Germany) were used. The surface characteristics of the DLIP-treated variants and TiPure Plus gritblasted and acid-etched reference material are shown in Table I.

As a positive control for the in vitro cytocompatibility tests, RM-A, a polyurethane film sheet containing $0.1 \%$ zinc diethyldithio-carbamate (Hatano Research Institute, Hadano, Kanagawa, Japan) was used. As a negative control, Wako plastic sheets (cat. no. 160-08893; Wako Chemicals GmbH, Neuss, Germany) were used. 
A

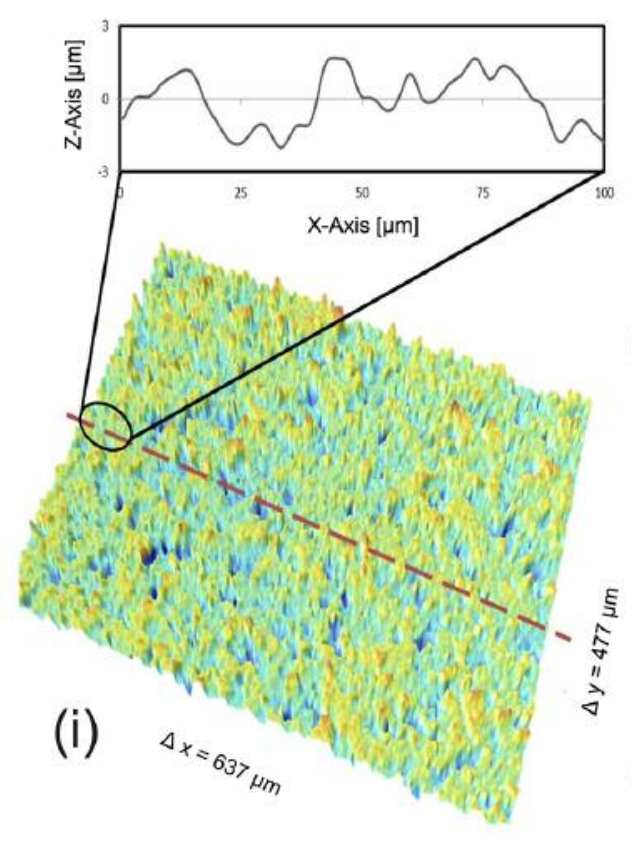

(ii)

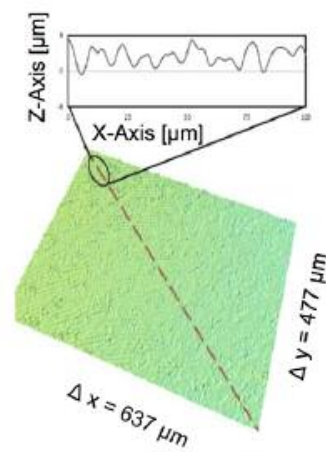

(iii)
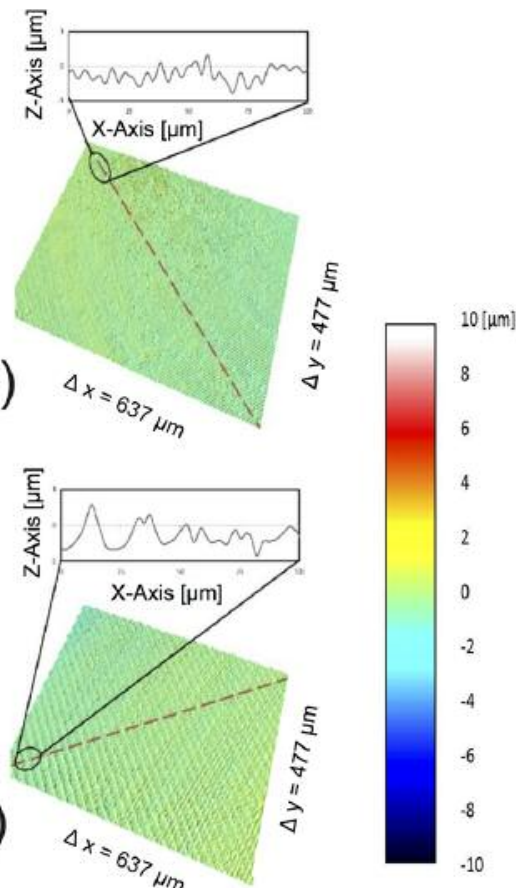

B
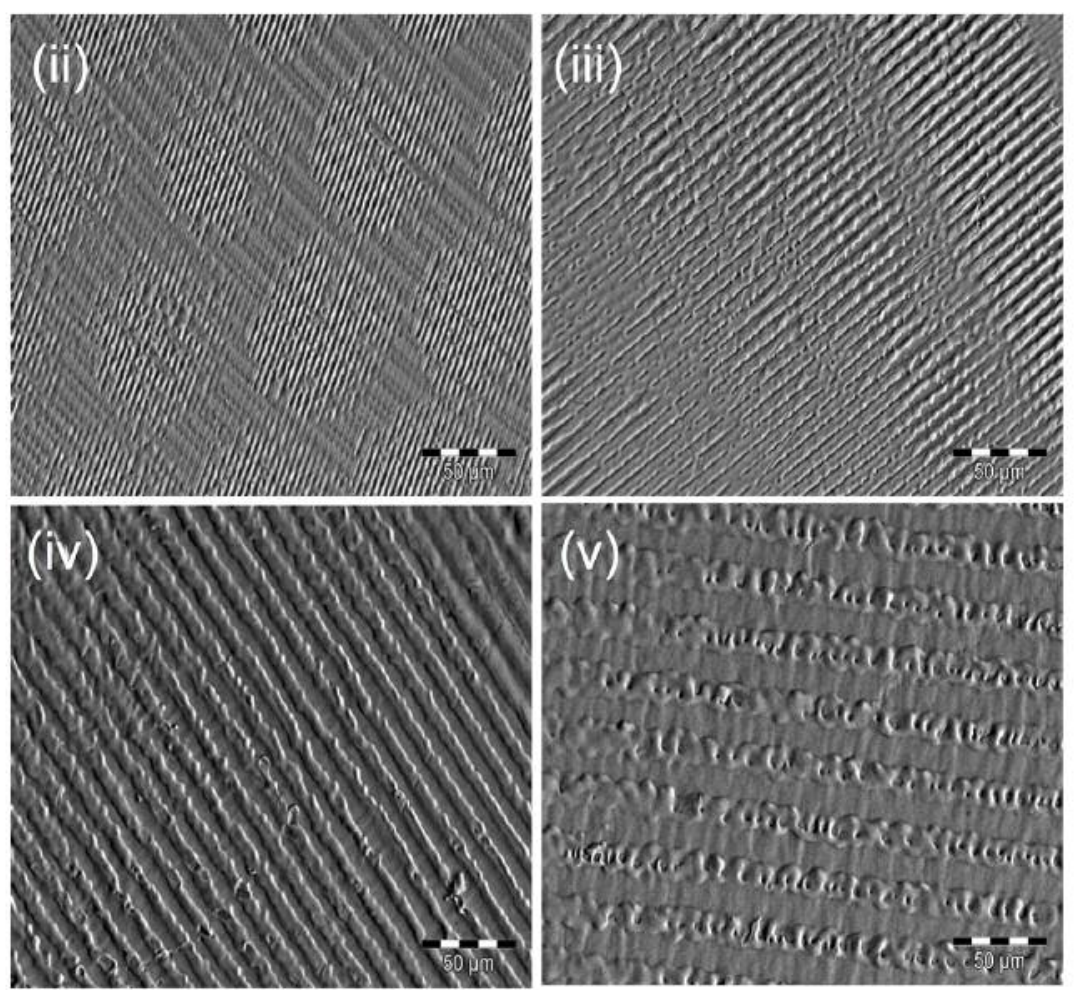

Figure 1. Plasma mass spectroscopy (A) and scanning electron microscopy (B) of the surface microstructure of the grit-blasted and acid-etched reference material ( ) and the laser-sintered variants: (ii) $3 \mu \mathrm{m}$ (iii) $5 \mu \mathrm{m}$ (iv) $10 \mu \mathrm{m}$ and (v) $20 \mu \mathrm{m}$. Bars: $50 \mu \mathrm{m}$. 

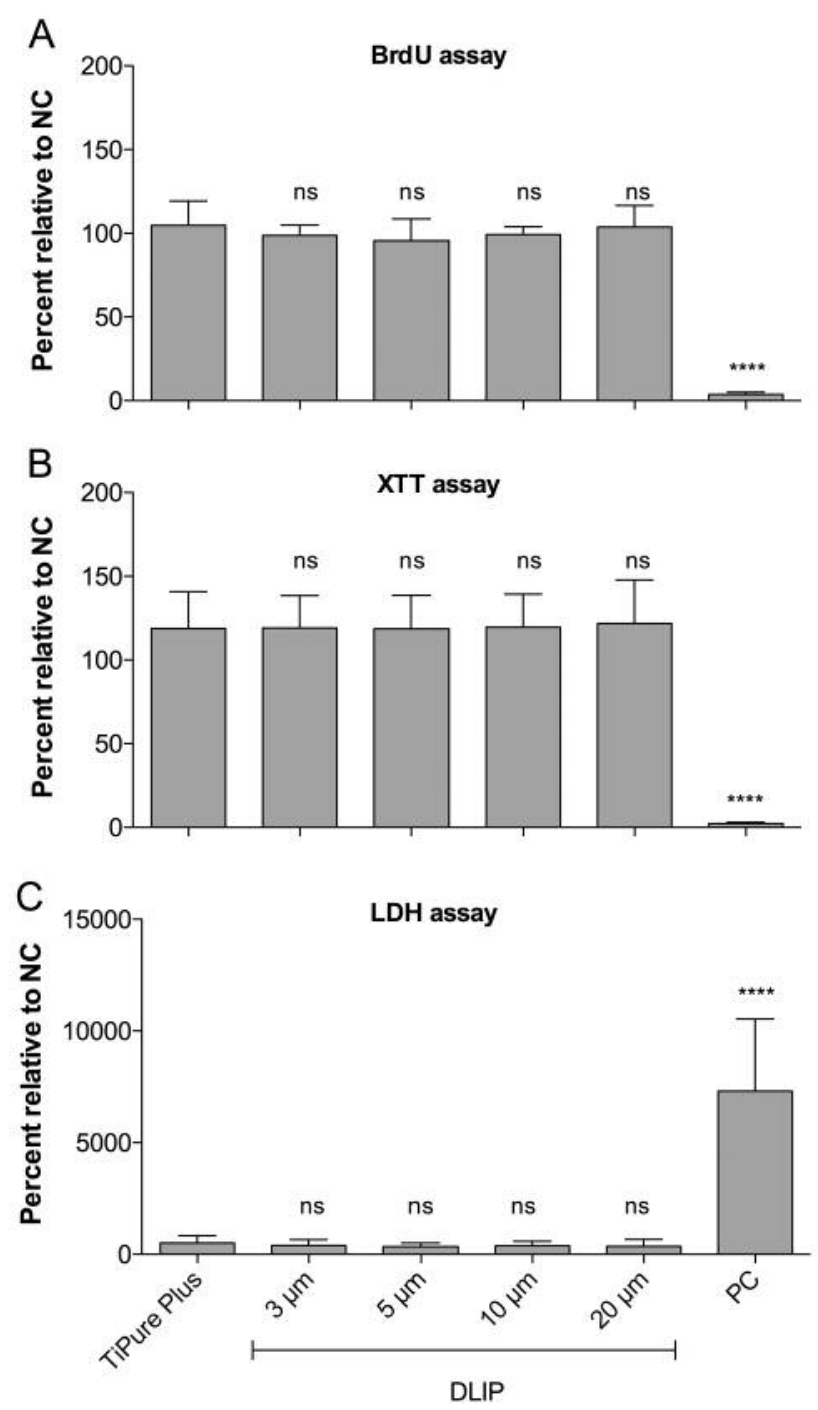

Figure 2. Indirect assays of cytocompatibility: Bromodeoxyuridine, (BrdU) (A), 2,3-Bis-(2-methoxy-4-nitro-5-sulfophenyl)-2H-tetrazolium5-carboxanilide $(X T T)(B)$, and lactate dehydrogenase $(L D H)(C)$. Blank control values (medium alone without cells) were subtracted from the absorbance values in all assays. All values were normalized to the negative control (NC, cells incubated with medium that was preincubated without specimens). Columns represent the mean values of quadruplicate measurements from incubation of cells with medium from six specimens per material. Error bars represent the standard deviation. ${ }^{* * *}$ Significantly different from $N C$ at $p \leq 0.001 ; n s:$ nonsignificant difference.

Cytocompatibility assays. All assays were carried out using the mouse fibroblast cell line L929; direct live-dead staining assay was carried out using L929 cells and the preosteoblast cell line MC3T3E1 (both from the American Type Culture Collection via LGC Standards GmbH, Wesel, Germany). The cells were maintained in their recommended medium under standard cultural conditions (6).
Table I. Surface characteristics of direct laser interference patterning (DLIP)-treated variants and TiPure Plus grit-blasted and acid-etched reference material. *The spatial period ( $p$ ) is given for each surface.

\begin{tabular}{lccc}
\hline Surface & $\begin{array}{c}\text { Surface } \\
\text { roughness } \\
(\mu \mathrm{m})\end{array}$ & $\begin{array}{c}\text { Peak to } \\
\text { valley height } \\
(\mu \mathrm{m})\end{array}$ & $\begin{array}{c}\text { DLIP structure } \\
\text { depth } \\
(\mu \mathrm{m})\end{array}$ \\
\hline TiPurePLUS & $1.21 \pm 0.03$ & $15.32 \pm 0.63$ & - \\
DLIP $(p=3 \mu \mathrm{m})^{*}$ & $0.35 \pm 0.01$ & $3.99 \pm 1.05$ & $0.59 \pm 0.32$ \\
DLIP $(p=5 \mu \mathrm{m})$ & $0.29 \pm 0.05$ & $3.55 \pm 0.35$ & $1.33 \pm 0.29$ \\
$\operatorname{DLIP}(p=10 \mu \mathrm{m})$ & $0.21 \pm 0.04$ & $3.51 \pm 0.38$ & $1.24 \pm 0.47$ \\
$\operatorname{DLIP}(p=20 \mu \mathrm{m})$ & $0.32 \pm 0.02$ & $5.71 \pm 1.10$ & $1.53 \pm 0.43$ \\
\hline
\end{tabular}

For L929 cells, minimum essential medium (MEM) supplemented with $10 \%$ fetal bovine serum, penicillin/streptomycin $(100 \mathrm{U} / \mathrm{ml}$ each) (all from Life Technologies, Carlsbad, CA, USA) and Lglutamine (Sigma-Aldrich, St. Louis, MO, USA) to a final concentration of $4 \mathrm{mM}$ was used. For MC3T3-E1, MEM $\alpha$ was used as base medium supplemented as per the L929 medium but without additional L-glutamine.

The assays for viability (2,3-bis-(2-methoxy-4-nitro-5sulfophenyl)-2H-tetrazolium-5-carboxanilide; XTT), proliferation (bromodeoxyuridine; BrdU) and for toxicity (lactate dehydrogenase; LDH) were carried out using established kits, as described in our previous publication both as direct assays and as indirect (extract) assays (7). Briefly, the indirect assays test possible soluble toxic substances from the test specimen by culturing cells for $24 \mathrm{~h}$ in medium that was previously incubated with the test specimens for 3 days. In direct assays, cells were seeded directly onto the surface of the test specimen and the assays were carried out 2 days later. Live-dead staining of cells that were cultured directly on the specimens was carried out 1 day later to determine cellular attachment and to visualize cytotoxic effects.

Data evaluation. Statistical analysis was performed using the software Graphpad Prism 5 (GraphPad Software, Inc., La Jolla, CA, USA). For differences between each test specimen and the gritblasted and acid-etched reference specimen, an ANOVA was performed with subsequent Bonferroni correction. All tests were two-tailed and the statistically significant level was set at 0.05 .

\section{Results}

Medium from incubation with the modified and the gritblasted and acid-etched reference titanium specimen did not alter any of the cytocompatibility parameters including cytotoxicity, viability and proliferation of the L929 cells (Figure 2). Medium cultured with the RMA reference material led to a complete lack of viability and proliferation, coupled with high cytoxicity (Figure 2).

Attachment of the cells to the modified surfaces was comparable to that of cells attached to the grit-blasted and acid-etched reference titanium surface (Figure 3). Moreover, 


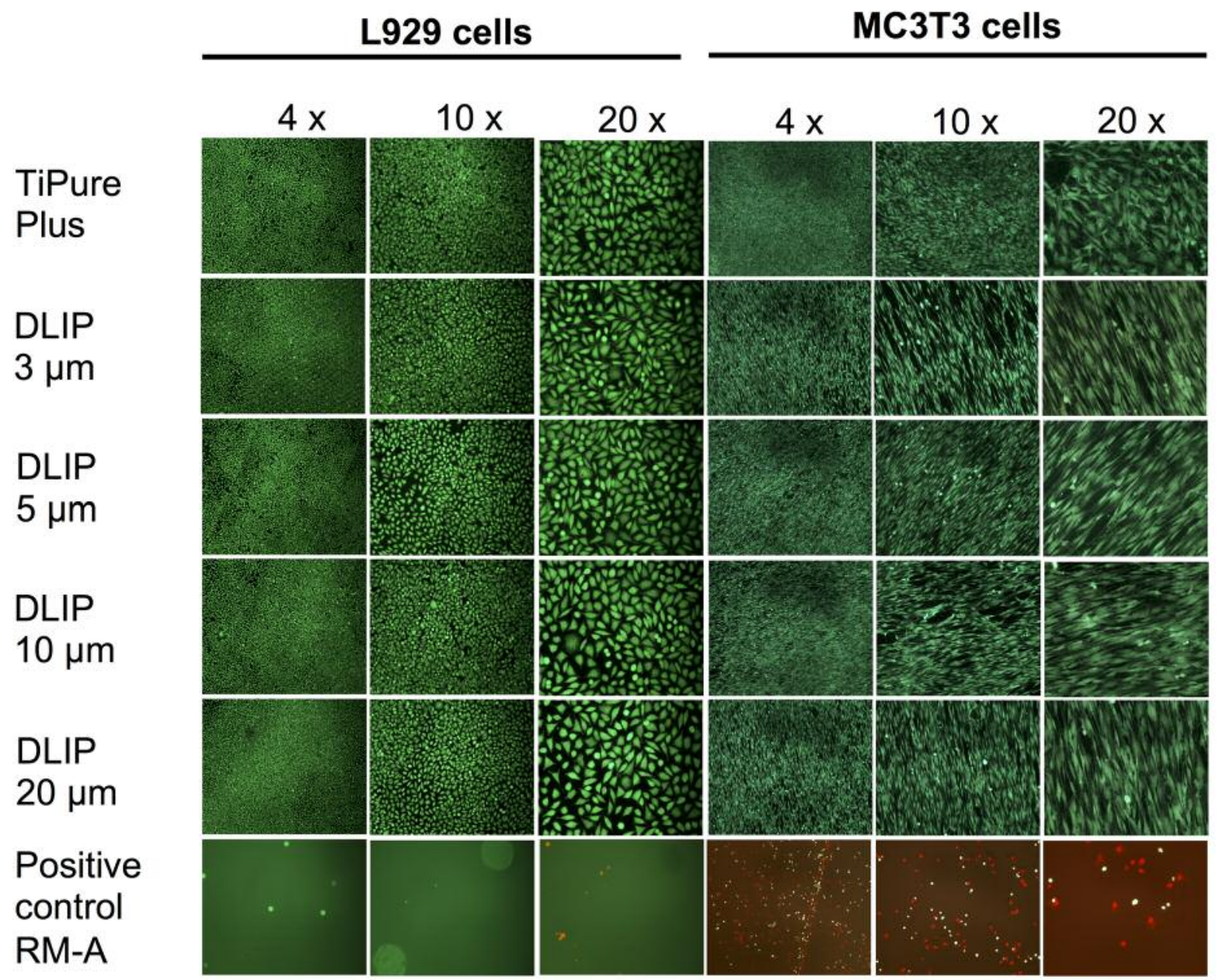

Figure 3. Live-dead staining. Cells were directly seeded on the different surfaces and cultured for $24 \mathrm{~h}$. Viable cells stained with fluorescein diacetate (green) and the nuclei of dead cells stained only with propidium iodide (red). Magnification used is given above the panels.

the cell morphology was not altered by the modifications. In concordance with this, viability and proliferation of the cells directly cultured on the specimens were similar on all the titanium surfaces, regardless of the laser modification used (Figure 4). Accordingly, no toxicity was detectable (Figure 4).

\section{Discussion}

In this study, we have shown that all four DLIP titanium surfaces preserved good cytocompatibility as regards cell attachment, viability and proliferation, in both indirect and direct assays.

Traditional approaches for generating roughness such as etching, are known to frequently lead to reduced biocompatibility. In vitro, cellular attachment, viability and proliferation may all be negatively influenced (8). By contrast, DLIP seems to be rather neutral regarding the cytocompatibility of the treated surfaces. This is reasonable because DLIP is a physical modification which neither leads to a release of toxic soluble substances nor toxic effects by direct contact. Nevertheless, certain surface structures may still inhibit cell attachment with the possible consequence of increased cytotoxicity, as well as reduced viability and proliferation. Indeed, previous studies have reported such phenomena (9).

No improvement in cytocompability was achieved for any of the four surface modifications. One possible explanation for the lack of positive effect of DLIP is that a change in pure physical roughness does not alter cytocompatibility features. It is also possible that the range of periodicity of the line-like structures that were chosen for this study (3-20 $\mu \mathrm{m})$ was too narrow to reveal any such alterations. Future studies may try 

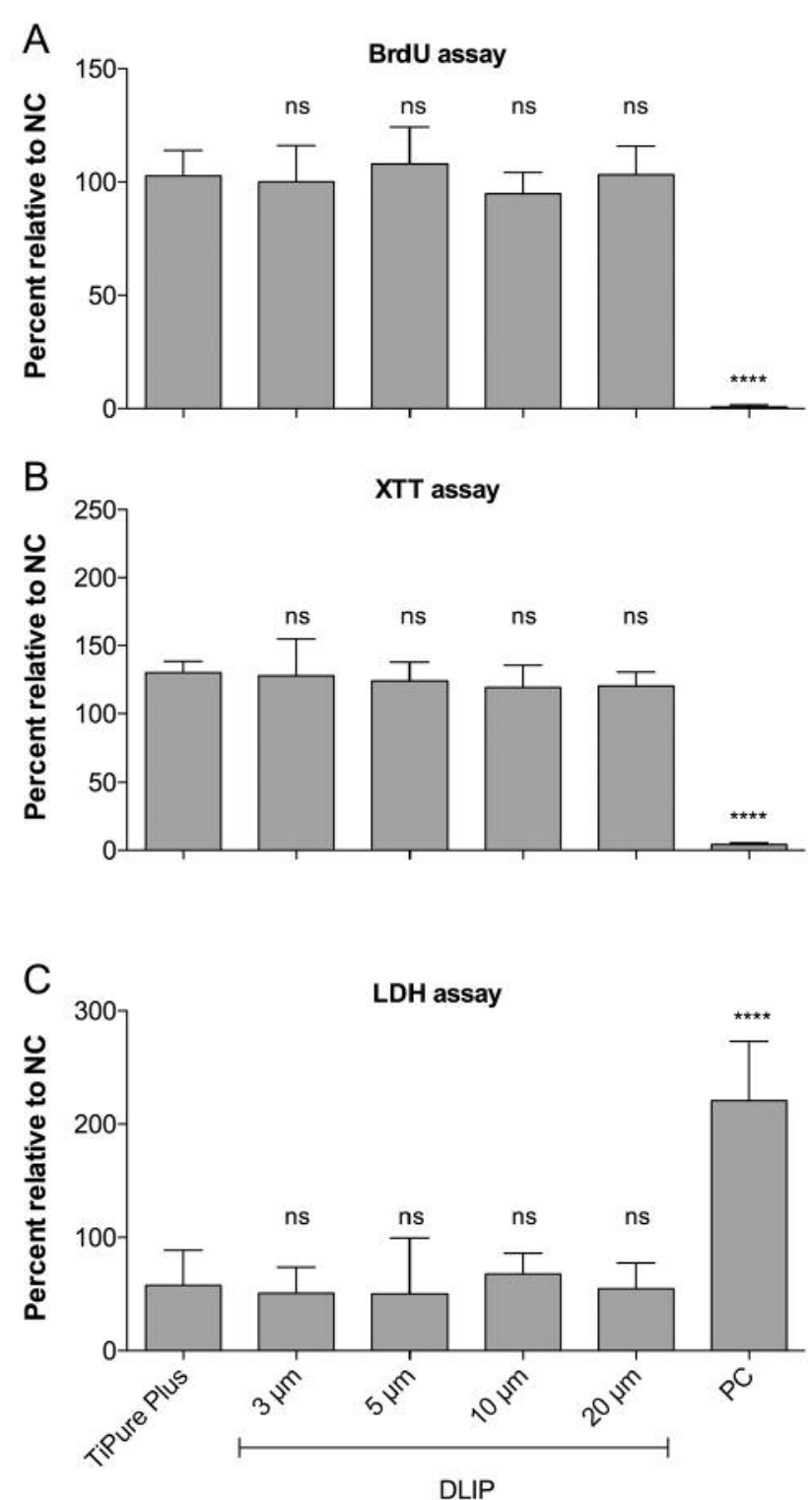

Figure 4. Direct assays of cytocompatibility: Bromodeoxyuridine, (BrdU) (A), 2,3-Bis-(2-methoxy-4-nitro-5-sulfophenyl)-2H-tetrazolium5-carboxanilide $(X T T)(B)$, and lactate dehydrogenase $(\mathrm{LDH})(\mathrm{C})$. Assays were performed with L-929 cells that were directly seeded and cultured $48 \mathrm{~h}$ on the laser sintered specimens. Blank controls (medium alone without cells) were subtracted from the absorbance values in all assays. All values were normalized to the negative control (NC, cells cultured on Wako plastic sheets). Columns represent the mean values of quadruplicate measurements from cells cultured on six specimens per material. Error bars represent the standard deviation. ****Significantly different from NC at $p \leq 0.001$; ns: non-significant difference.

surfaces with line-like structures with spatial periods smaller than $3 \mu \mathrm{m}$ as well as larger than $20 \mu \mathrm{m}$. Previous studies demonstrated that roughing the surface of titanium seems to have the potential of promoting osseointegration $(9,10)$.
Even though the results obtained and those of previous studies indicate that DLIP might yield more promising osseointegration results, such a conclusion requires further in vivo testing with progressive monitoring of the osseointegrative state over regular time intervals starting from implant loading.

In summary, laser-structured titanium implants do offer a more favorable surface for viable cell attachment and represent a superior alternative to conventional roughening, such as acid etching and grit blasting (11). Furthermore, the viability of the attached cells is an important indicator for future successful implant treatment since the cells themselves are the primary elements expected to react and be stimulated into continuing along the path of osteoblastic differentiation to achieve the ultimate goal of osseointegration of a functional implant into bone union.

\section{Disclosure}

MGH and NG are employed by BEGO Implant Systems GmbH \& Co. KG, a company that produces dental implants.

\section{Acknowledgements}

The Authors thank Lan Kluwe for her contribution in preparing the article.

\section{References}

1 Mangano F, Chambrone L, van Noort R, Miller C, Hatton P and Mangano $\mathrm{C}$ : Direct metal laser sintering titanium dental implants: A review of the current literature. Int J Biomater 2014: 461534, 2014.

2 Lasagni AF, Roch T, Langheinrich D, Bieda M and Wetzig A: Large area direct fabrication of periodic arrays using interference patterning. Lasers in Manufacturing 2011: Proceedings of the Sixth International Wlt Conference on Lasers in Manufacturing, Vol 12, Pt B 12: 214-220, 2011.

3 Lasagni AF, Holzapfel C and Mücklich F: Periodic pattern formation of intermetallic phases with long range order by laser interference metallurgy. Adv Eng Mater 7: 487-492, 2005.

4 Lang V, Roch $\mathrm{T}$ and Lasagni AF: World record in high speed laser surface microstructuring of polymer and steel using direct laser interference patterning. Laser-Based Micro Nanoproc X 9736: 97360Z, 2016.

5 Dahotre NB, Paital SR, Samant AN and Daniel C: Wetting behaviour of laser synthetic surface microtextures on ti-6al-4v for bioapplication. Phil Trans R Soc A 368(1917): 1863-1889, 2010.

6 Jung O, Smeets R, Porchetta D, Kopp A, Ptock C, Muller U, Heiland M, Schwade M, Behr B, Kroger N, Kluwe L, Hanken $\mathrm{H}$ and Hartjen P: Optimized in vitro procedure for assessing the cytocompatibility of magnesium-based biomaterials. Acta Biomater 23: 354-363, 2015.

7 Jung O, Smeets R, Kopp A, Porchetta D, Hiester P, Heiland M, Friedrich RE, Precht C, Hanken H, Grobe A and Hartjen P: Peogenerated surfaces support attachment and growth of cells in vitro with no additional benefit for micro-roughness in sa (0.2$4 \mu \mathrm{m})$. In Vivo 30(1): 27-33, 2016. 
8 Mangano C, De Rosa A, Desiderio V, d'Aquino R, Piattelli A, De Francesco F, Tirino V, Mangano F and Papaccio G: The osteoblastic differentiation of dental pulp stem cells and bone formation on different titanium surface textures. Biomaterials 31(13): 3543-3551, 2010.

9 Mangano C, Raspanti M, Traini T, Piattelli A and Sammons R: Stereo imaging and cytocompatibility of a model dental implant surface formed by direct laser fabrication. J Biomed Mater Res A 88(3): 823-831, 2009.

10 Hyzy SL, Cheng A, Cohen DJ, Yatzkaier G, Whitehead AJ, Clohessy RM, Gittens RA, Boyan BD and Schwartz Z: Novel hydrophilic nanostructured microtexture on direct metal laser sintered ti-6al-4v surfaces enhances osteoblast response in vitro and osseointegration in a rabbit model. J Biomed Mater Res A 104(8): 2086-2098, 2016.
11 Prodanov L, Lamers E, Wolke J, Huiberts R, Jansen JA and Walboomers XF: In vivo comparison between laser-treated and grit blasted/acid etched titanium. Clin Oral Implants Res 25(2): 234-239, 2014.
Received July 7, 2017

Revised August 2, 2017

Accepted August 4, 2017 